\title{
Troubleshooting Forum
}

\section{Molecular Biology Techniques Q\&As}

Since October 2002, the Molecular Biology Forums* have brought questioners and experts together in an online community to solve tough laboratory problems. This month's questions come from the "Real-Time qPCR/qRT-PCR Methods" and "Protein Methods" forums, respectively. We have edited the posts lightly, for clarity. Mentions of specific products or manufacturers are retained from the original posts. They do not represent the opinions of BioTechniques.

\section{How can I compare gene expression across species? (Thread 19154)}

Q I am just wondering if anyone can help me with a reference to a paper on the comparison of genes across species of animals. I am trying to quantitate, relative or otherwise, a specific gene across murine, human, and bovine samples.

- I have run glutamate dehydrogenase for all these samples, but can I just normalize against GDH for each species and be able to compare the normalized values for the gene of interest?

- Is this a biologically sound way to express the data?

- Perhaps there is difference in GDH expression across species?

A1 Try this paper: Vandesompele J., et al., 2002. Accurate normalization of realtime quantitative RT-PCR data by geometric averaging of multiple internal control genes. Genome Biol. 3(7):RESEARCH0034.

These authors compare different human tissues instead of different species, but they explain the process for selecting the right housekeeping genes quite well. I think GDH isn't a bad choice, but I would use more than one gene for the normalization. It minimizes errors.

A2 The difference in GDH (or any other reference gene) expression across species can be measured when the samples are normalized to the amount of total RNA or 18S RNA per reaction. The amount of ribosomal RNA should be similar across species, at least in the same type of tissue. The approach described by Vandesompele et al. (geometric averaging of multiple internal control genes) is of course excellent, but expensive and laborious.

\section{Will zymography show aspartic protease activity? (Thread 19260)}

Q Should I use zymography for the following situation?

We are trying to determine if any aspartic proteases play a role in the mechanism of action for a small molecule inhibitor that we have. The small molecule is an anti-viral drug. We have no idea what the drug does specifically, but we want to see if it targets these proteases since they are responsible for glycoprotein processing for the virus.

A colleague wants to run a gelatin zymogram with the cell lysate to identify any aspartic proteases that might play a role in the mechanism of action. If we added pepstatin or other inhibitors along with it, we could possibly see a difference in all the other proteases that are going to cleave the gelatin. But even then, we have to identify the bands and who is to say that the conditions of the gel $(\mathrm{pH}$, etc.) are going to be ideal for proteolysis of any number of the different aspartic proteases anyway?

I think that the main reason he wants to run this is because it is inexpensive. Does anyone know a better way to utilize this method so at least it makes sense?

A1 It seems to me that if you want to see if the inhibitor inhibits aspartic proteases, you can do an aspartic protease-specific assay (with and without known aspartic protease) in tubes or microtiter plates. Zymogram is nonspecific.

*Visit the Molecular Biology Techniques Forums online at molecularbiology.forums. biotechniques.com/forums/

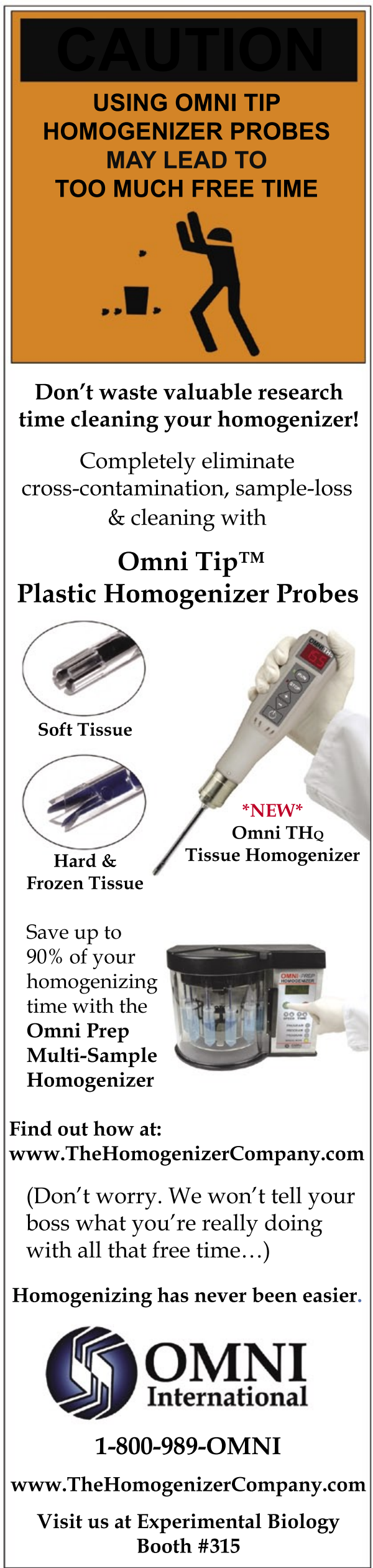

Circle Reader Service No. 142 